\title{
TUBE-TO-SHEET JOINTS OF DISSIMILAR MATERIALS USING COMBINED PLASTIC DEFORMATION PROCESS IN SINGLE PASS
}

\author{
Samy Zein El-Abden \\ Production Engineering and Mechanical Design Dept., Faculty of Engineering, Minia University, \\ Minia, Egypt, postal code 61111 \\ *Corresponding author E-mail: sami.zein@minia.edu.eg
}

\begin{abstract}
Joining by plastic deformation is needed in applications such as joining of similar and dissimilar metal parts, fluid transmission pipeline, aircraft and automobile components. This paper presents a new plastic deformation technique to connect sheet to tube in one pass of dissimilar material. A single pass joining is accomplished to produce bosses and a tube lip edge over flat sheet. The tube constrained length and tube lip height were checked by finite element analysis (FE) and experimental testing. Aluminum tube specimens with $48 \mathrm{~mm}$ outer diameter and $2 \mathrm{~mm}$ initial thickness were used. Tube lip height of 6, 8, 10, 12 and $14 \mathrm{~mm}$ and constrained length of 6, 8, 10, $15,20,25,30$ and $35 \mathrm{~mm}$ were used to form the boss part. Minimum punch nose radius was used to produce severe deformation of the tube lip over sheet surface as well as to avoid the tube lip curls. The tube passes through several stages until it is connected with the metal sheet, partial flare-bend, partial boss forming and the seaming stage. A new design of the punch was used to control the internal tube diameter and prevent the inward tube flow during the deformation process. Good agreement was found when comparing $\mathrm{FE}$ to experimentally-obtained results concerning deformation stages, trend of load/displacement curves.
\end{abstract}

Keywords: Single pass plastic deformation joining, Sheet to tube joinin, Boss forming, Dissimilar materials joining, F.E analysis, Process parameters.

\section{INTRODUCTION}

An advancement of joint applications in modern industry has become increasingly important for economic reasons and in terms of environmental protection as well as improving the mechanical properties of the Received: 25 November, 2019, Accepted: 15 December, 2019 obtained joint. The normal joining techniques such as arc welding or resistance spot welding can only be used for joining similar material parts. The mechanical plastic deformation joining process can be used for forming of net-shape annular boss in hollow tubes over 


\section{Vol. 40, No. 1. January 2021}

the upper surface of bottom die. Special emphasis has been placed on this work on the utilization of the plastic deformation technique which is also designated as axial compression and external inversion stags. The major process parameters and the deformation mechanics for sheet-bulk forming of thinwalled tubes were investigated by [1]. The ratio between initial gap length (constrained length) and the final wall thickness was adapted more than 10 times. The process is mainly limited by the corner radius of the inversion die because inexistent (or very small) corner radius will give rise to plastic instability of the upper tube end, whereas large corner radius will bend the sheet along its radius. The internal mechanical locking technique at the ambient temperature for connecting two tubes by their ends was studied by [2]. They presented a mechanical joining process based on the plastic deformation by crimping or local instability of the tube ends. The total length of the reduced tube end, the end rounding die corner radius and the corner radius of the mandrel as the major parameters which affected the joint efficiency..

Ref. []], focused on improving utilizations of the deformation modes of end tube forming for joining sheet to thin-walled tubular profiles. They concluded that, the ratio between the initial gap height and the reference radius of the tube must be large enough to enable a tube bead to be formed by axial compression load and small enough to avoid the development of inward material flow inside the tube. The complete joint was carried out through two individual stages (axial compression and external inversion) shown in Fig. 1. Ref. [4] presented a new process to produce boss forming for introducing annular flanges using axial compression of tube wall thickness. The process was established to allow piling-up more material without buckling or cracking to be formed of the annular flange. The required boss forming force with displacement is typical of the closed-die forming operations with a rapid increase in the last stage of deformation due to restrictions in material flow caused by the die cavity.

Dissimilar materials with different strengths were joined by plastic deformation process, [5]. The process consists of two elementary tube forming operations that are carried out in a single stroke; expansion to produce two adjacent counters facing surfaces and compression beading to lock the tubes together, the opposite equipped axial dies were used to complete the connection. Plastic instability waves in thin-walled tubes generated from axial compression to produce tube attachment were studied by []․ The slenderness ratio between the unsupported free length of the tube and the inner radius of the tube has the great effect of the instability generated. The internal mandrels have a strong effect on the plastic instability in tube joining for avoiding the development of unacceptable inward plastic flow and to prevent compression bead sleeve was used.

Buckling and manufacture efficiency for sidewall thickening was studied by [7], one stage upsetting operation along the longitudinal direction of the sheet assisted by a counter punch under constant back pressure were made to control the buckling in tube wall thickness. Single-stroke mechanical joining process was carried out by []], several 
operative variables controlled the sources of failure in the final product. Ref. [9], presented a rotary swaging technique for joining tube to tube work-part of plastic deformation method. Better strength joint was obtained when the distance from the end of the inner tube to the center of the hammer die increased over 5 $\mathrm{mm}$; the values of stress and strain were obtained at the joining portion and variation in thickness of the two joined tubes is small.

New developments in boss forming of tubes to fix the sheets at ambient temperature were made by [10]; boss formed by partial compression of the tube wall thickness along the straight direction which allow metal to be accumulated and robust annular flanges. Mechanical lock can be obtained with the upsetting of the free tube end against a sheet with a beveled hole. Ref. [11] proposed the plastic deformation joining of two thin-walled tubes by compression instability. It was concluded that the formability of the tubular plastic joining by compression instability could be assessed by geometrical parameters of the deformable tubes. Three joint modes were obtained immature, qualified and unqualified joints which were dependent on the ratio of the constrained length to the radius of the tube.

Ref. [12] presented a plastic cold joining method to joints a rotor shaft with a flange by indenting the serrated shaft having different teeth shape into the flange hole. It was concluded that the yielding strength of the joint was 1.5 times as high as mechanically fit joint.
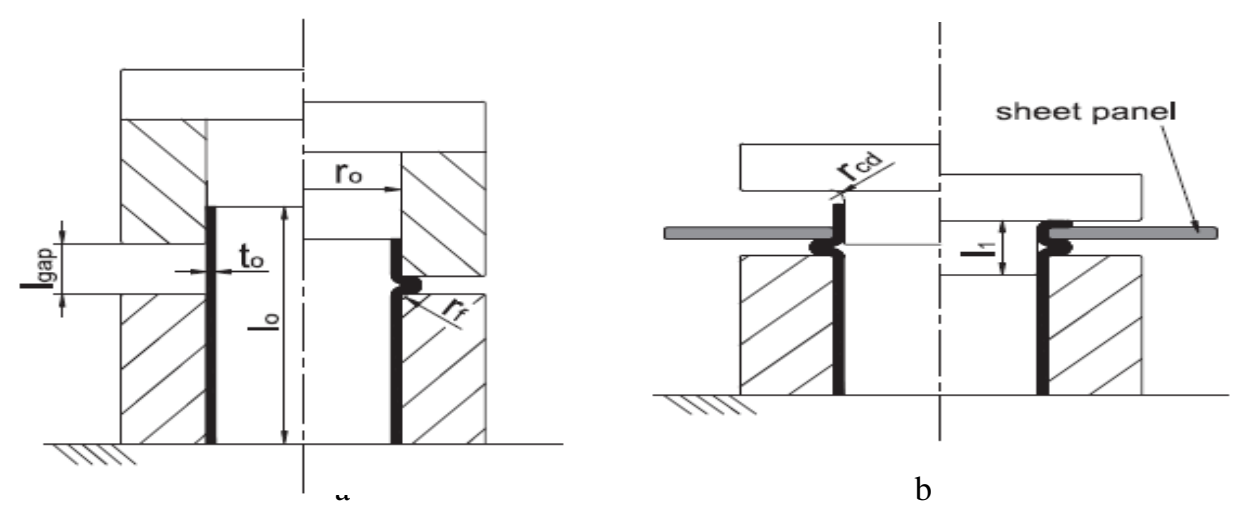

Fig. 1: Sheet-to tube joining process [3], a- Stage one axial compression and, b- Stage two external inversion

The objective of present work is to accomplish a new single pass joining plastic deformation process instead of multi-passes and to check the effect of tube lip height and constrained length on the load/displacement curves. A new design of the internal punch to prevent the inward flow of the tube material during the boss formation part was made.
Finite element (FE) modeling and experimental work will be carried out and compared.

\section{FINITE ELEMENT (FE) ANALYSIS}

A three dimensional finite element model has been followed for simulating the single 


\section{Vol. 40, No. 1. January 2021}

pass plastic deformation joining method using DEFORM Ver.11 (PC). The total time period for simulation has been adjusted according to tube lip height and constrained length of the tube. The die and punch have been assumed as rigid parts with a required geometry, while tube and sheet has been assumed as deformable parts. The tube and sheet are modeled based on the material have same property in all directions (isotropic). The effect of temperature was ignored. Friction between rigid and deformable parts was specified.

\section{1 boundary conditions}

The die is fixed, tube lower lip edge was constrained from movement in vertical direction (Z-axis), and the punch has been given a downward vertical displacement according to chosen parameters toward the upper lip edge and constrained length of deformable tube, Fig.2 shows the boundary condition and constrained of single pass plastic deformation joining process. The total number of tube elements created is approximately 62144 , while the total number of nodes created is approximately 15384 and the total number of surface polygons created is approximately 19306 with solver was used conjugate gradient. Table 1 gives the parameters in single pass plastic deformation joining process.

Table 1 Parameters in single pass plastic deformation joining process

\begin{tabular}{|l|l|l|}
\hline \multicolumn{1}{|c|}{ parameter } & Symbol & \\
\hline Tube lip length, mm & $\mathrm{H}$ & $6,8,10,12$ and 14 \\
Steel sheet thickness, mm & ts & 2 \\
constrained length, mm & Hc & 3 to, 4to, 5to, 7.5to, 10to, 12.5to, 15to and \\
Outer radius of deformable tube, mm & ro & 17.5 to \\
Tube thickness, mm & to & 24 \\
Punch nose radius, mm & $\mathrm{R}$ & 2 \\
Tube inner radius, mm & ri & 2 \\
Coefficient of friction & $\mu$ & 22 \\
Yield stress (MPa) & $\sigma y$ & $(0.05)$, grease-lubricated condition \\
Strength coefficient (MPa) & $\mathrm{k}$ & 38 \\
Strain hardening exponent (-) & $\mathrm{n}$ & 135 \\
Coefficient of friction (-) & $\mu$ & 0.24 \\
& & 0.05 \\
\hline
\end{tabular}


Vol. 40, No. 1. January 2021

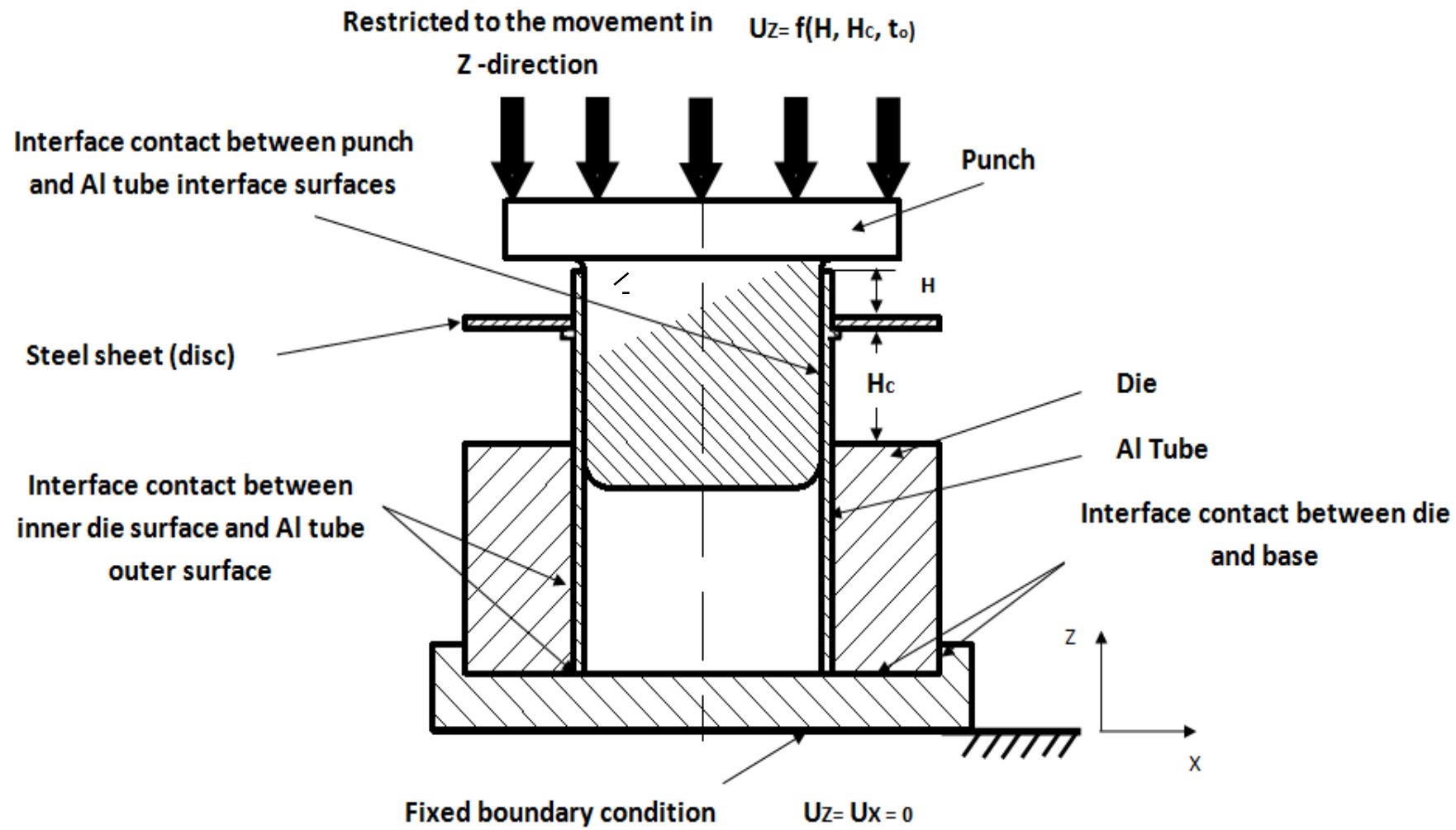

Fig. 2: Boundary conditions and constraints of single pass plastic deformation joining process

\section{SIMULATION RESULTS}

A sample of the FE predicted load/displacement curve accompanied by three obtained deformation stages in single pass plastic deformation joining process is shown in Fig.3. Figure $4 \mathrm{a}$ shows the beginning and the end of the three obtainable deformation stages of the process from the $\mathrm{FE}$ program. Fig. $4 \mathrm{~b}$ show sample of the stress distribution obtained from the simulation joining process. The stress in the joining zone between the tube and steel sheet is high due to insert the punch inside the tube with flarebend of the tube lip height 
Vol. 40, No. 1. January 2021

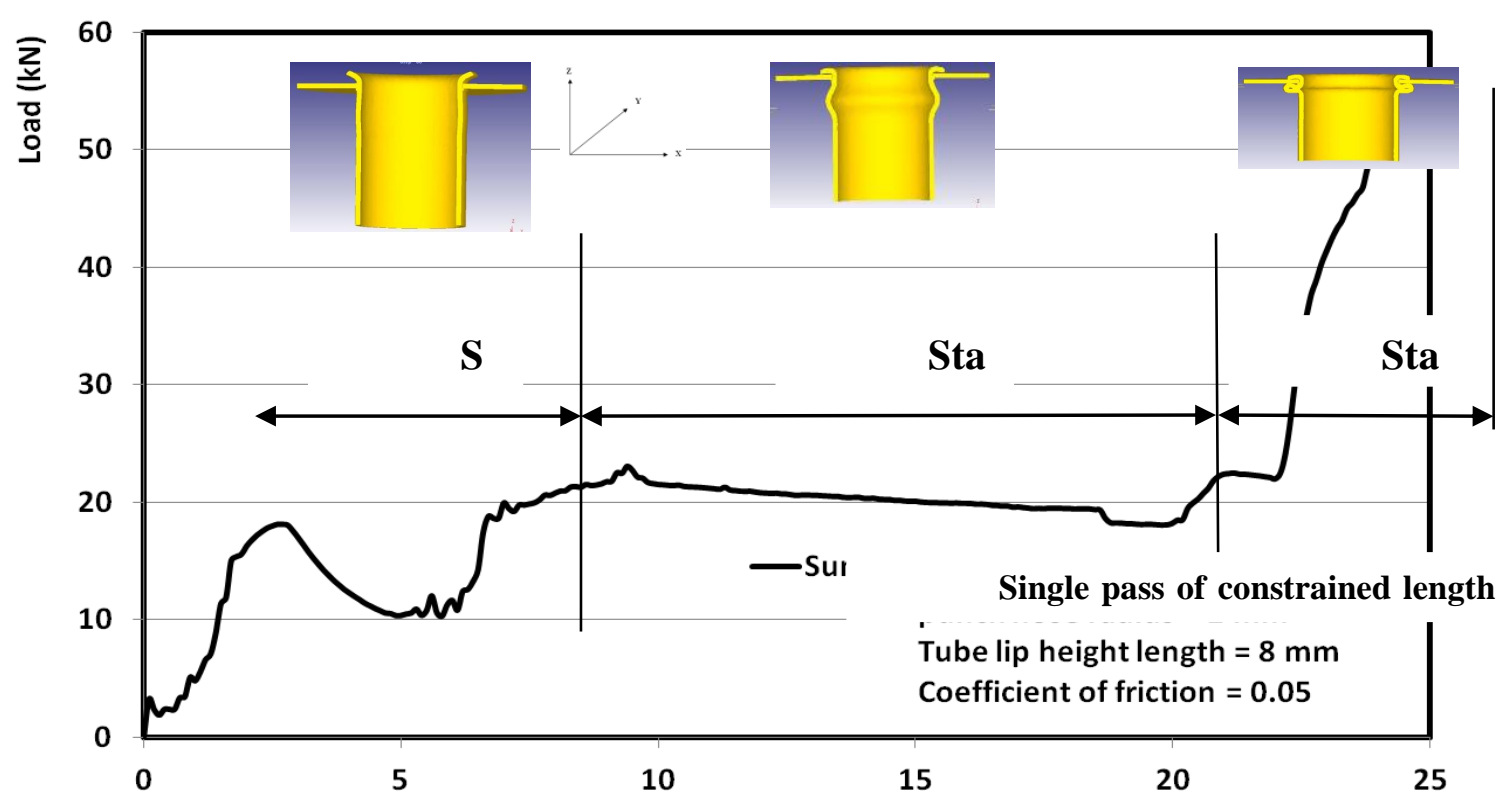

Fig. 3: FE predicted load/displacement deformation curve of the single pass plastic joir

Displacem different stages, punch nose radius $2 \mathrm{~mm}$, tube lip height $8 \mathrm{~mm}$ and constrained length $20 \mathrm{~mm}$ with 0.05 coefficient of friction

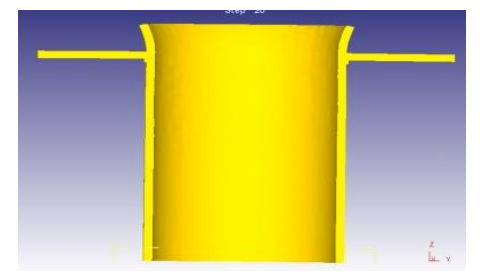

Beginning

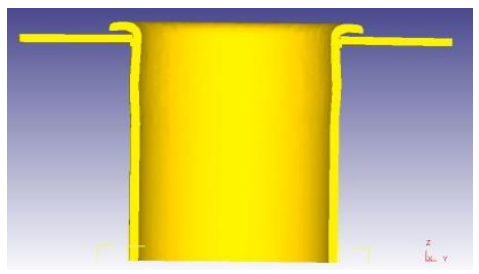

End

\section{Stage one (partial flare-bending)}

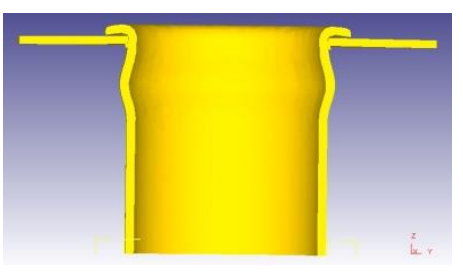

Beginning

Stage two (partial boss forming)

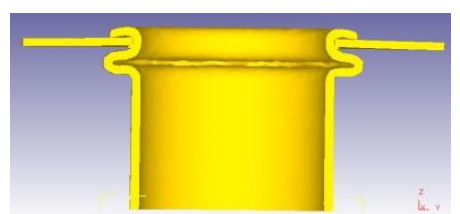

End

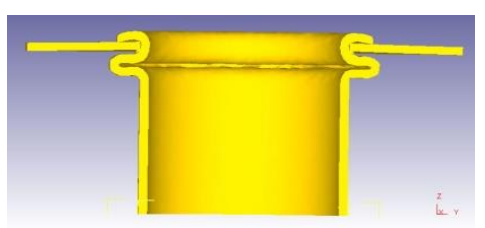

Beginning

Stage three (seaming)

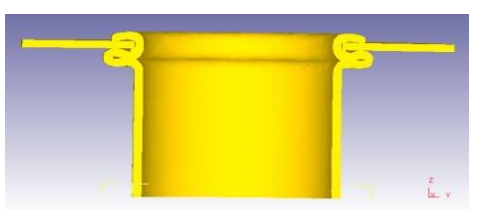

End

Fig. 4a: Obtainable deformation stages of single pass plastic deformation process from FE program 
Vol. 40, No. 1. January 2021

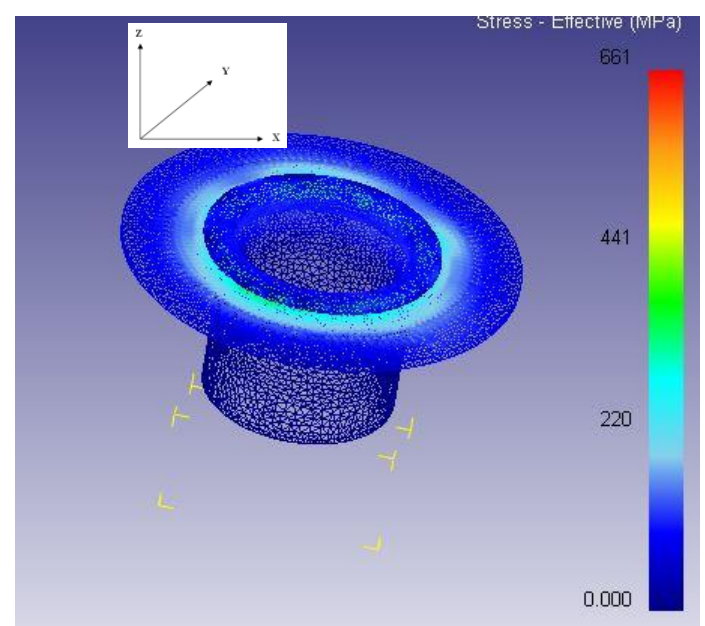

Fig. 4b: shows sample of the stress distribution obtainable from the simulation joining process

\subsubsection{Seaming}

In the third stage, after partial flaring and bossing was adopted, the load increases when complete closing of boss will occurs. Followed by slight reduction in the recorded load, where the upper lip is complete flattened on the upper face of steel sheet and then the load suddenly increases.

\subsection{FE predicted load displacement curves}

The FE-predicted load/displacement curves, at different constrained length $(6,8$, $10,15,20,25,30$ and $35 \mathrm{~mm}$ ), constant punch nose radius $(2 \mathrm{~mm})$ and different tube lip height $(6,8,10,12$ and $14 \mathrm{~mm})$ are shown in Fig. 5, (a, b, c, d and e). Friction coefficient between nosed punch and lip tube height is assumed to be 0.05 . It is observed from the figures that, all curves were identical in the trend in first, second and third deformation stages of large constrained length, but with differences in the values. The tube lip height affects the maximum and minimum load in the first stage. The maximum load obtained in the first stage occurred at minimum chosen of the lip height due to severe bending of small

\subsection{Stages of single pass Plastic deformation joining}

\subsubsection{Partial flare -bending}

When the punch is inserted in the upper tube end, the tube lip height material will move along the profile of punch nose due to punch pressure, the tube begins to flare partially. The flare-bend load gradually increases with the advancement of the tube lip along the contour of punch nose radius reached to a maximum load value at complete contact. Hence, the metal will bend and the load decreases to the smallest value at the end of this stage.

\subsubsection{Partial boss forming}

The second stage begin when the flared metal contacts and unilateral with the upper surface of the steel sheet, where the load again increases due to constrained upper and lower tube length and this leads to non-discontinuity of deformation and bulging. Hence, the load decreases to reach a minimum value at the end of this stage. 
third deformation stages. The decay rate increases with decreasing the constrained length, where the required load to complete the process increases. lip height. Moreover, the configuration of the load/displacement was greatly affected by the constrained length. As decreasing constrained length this leads to decay in the second and

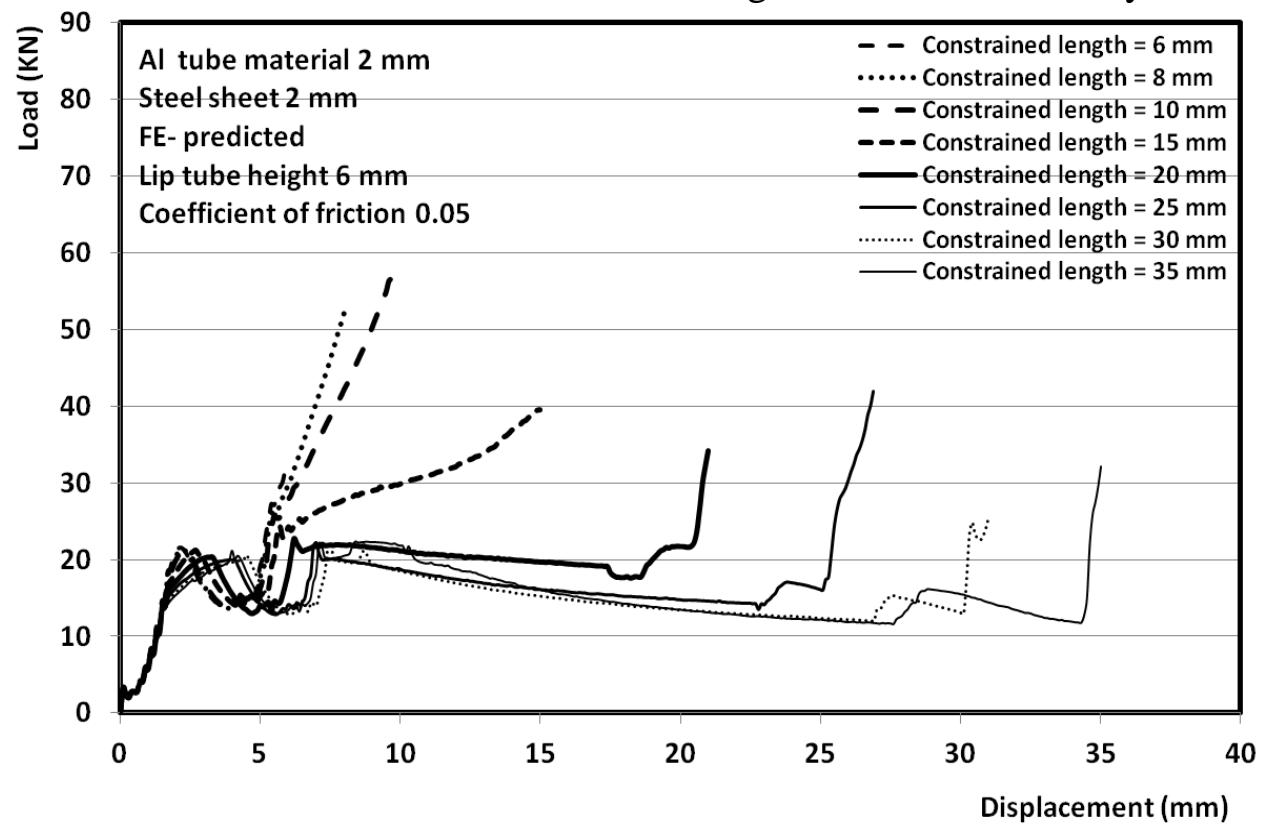

Constrained length of $6,8,10,15,20,25,30$ and 35, with tube lip height $6 \mathrm{~mm}$

(a)

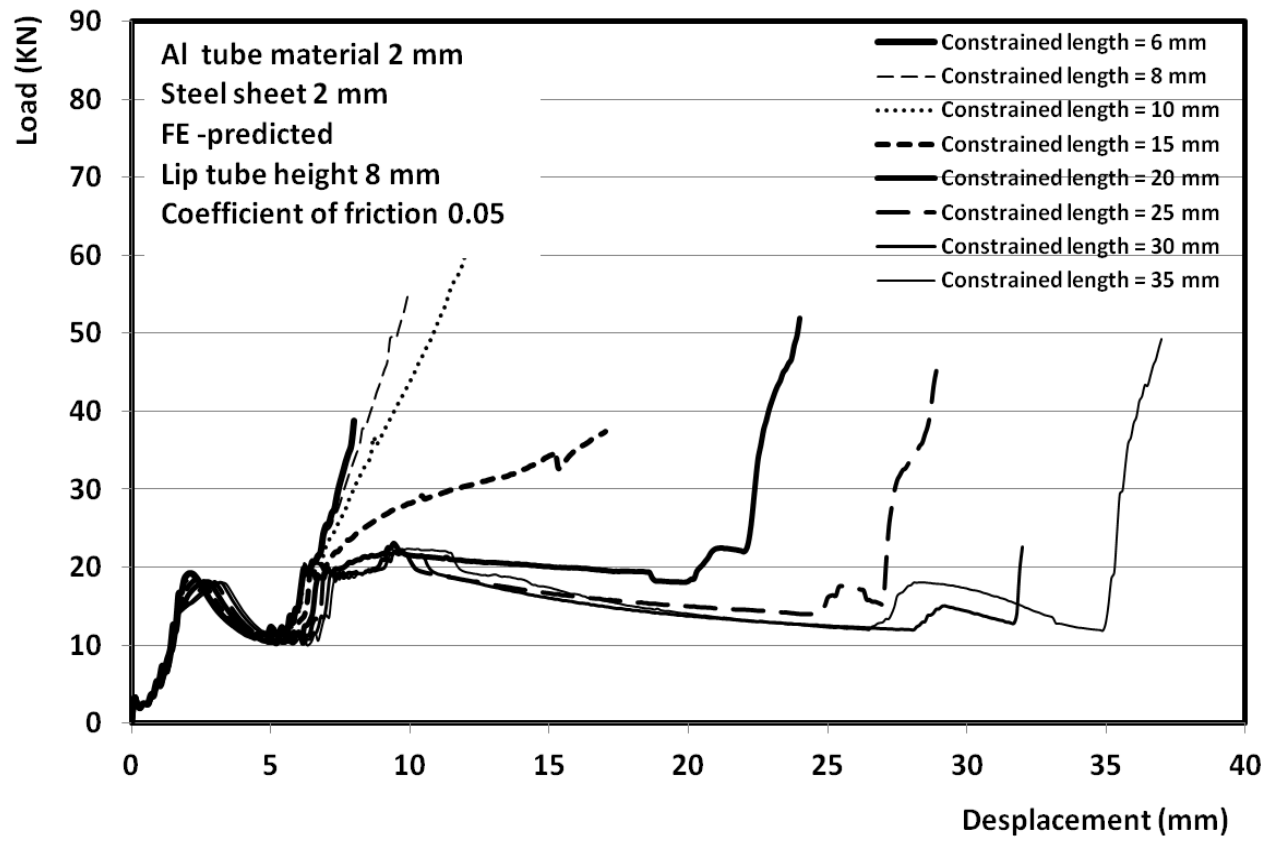

Constrained length of 6, 8, 10, 15, 20, 25, 30 and 35, with tube lip height $8 \mathrm{~mm}$ 
Vol. 40, No. 1. January 2021

(b)

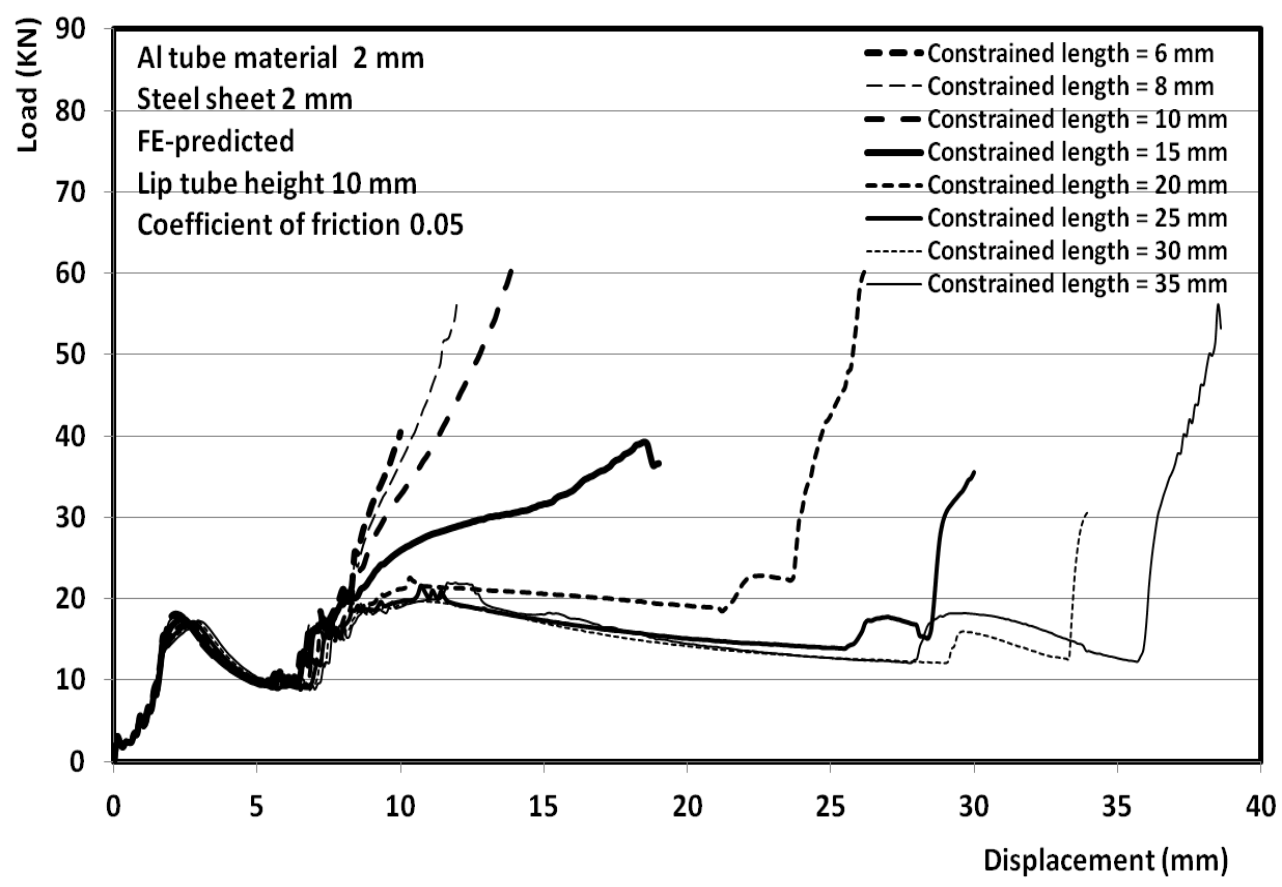

Constrained length of $6,8,10,15,20,25,30$ and 35 , with tube lip height $10 \mathrm{~mm}$

(c)

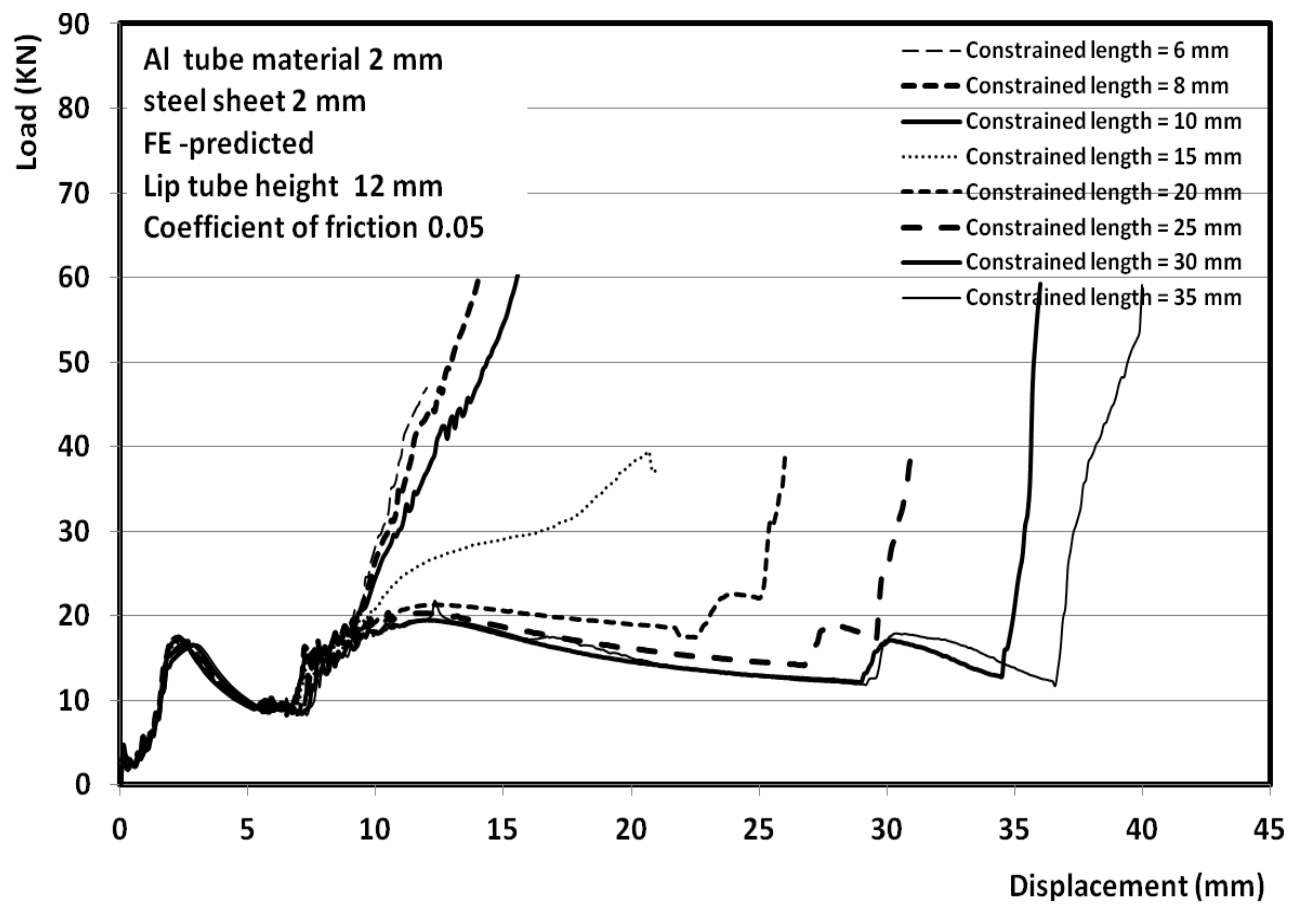

Constrained length of $6,8,10,15,20,25,30$ and 35 ,

with tube lip height $12 \mathrm{~mm}$ 
Vol. 40, No. 1. January 2021

(d)

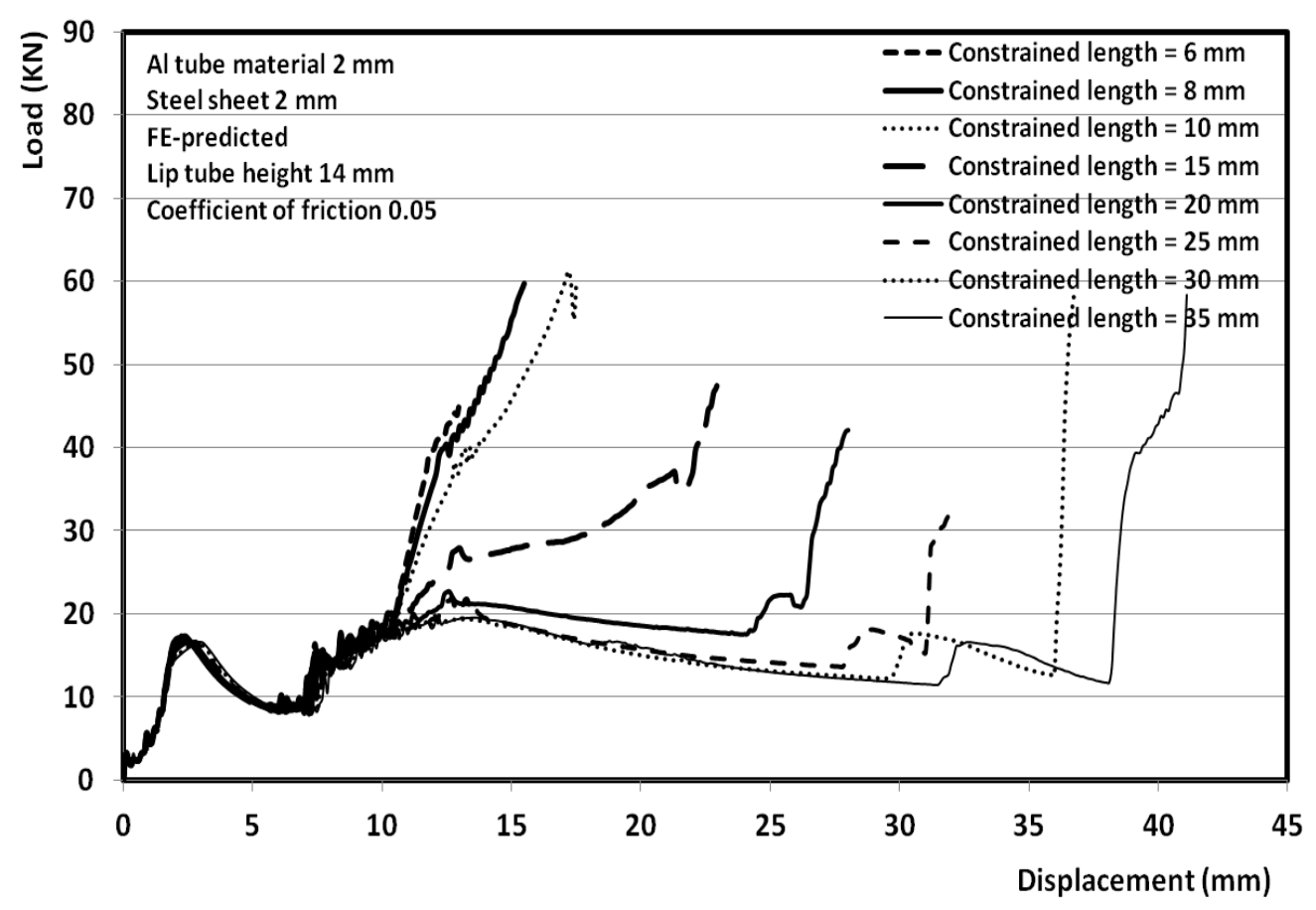

Constrained length of 6, 8, 10, 15, 20, 25, 30 and 35,

with tube lip height $14 \mathrm{~mm}$

(e)

Fig. 5: FE predicted load/displacement curves of different constrained length, different tube lip height, Coefficient of friction 0.05 and $2 \mathrm{~mm}$ punch nose radius

\section{EXPERIMENTAL WORK}

Tubular specimens of commercial-purity aluminum tubes, having an outer radius of 24 $\mathrm{mm}$ and thickness of $2 \mathrm{~mm}$ were prepared by machining operation. The sheet flange having an internal diameter of $48 \mathrm{~mm}$ is installed at the outer diameter of the tube at the required position at the upper tube end. The experiments set-up and the part details are shown in Fig. 6. The tube is constrained by the lower die, to fix the lip of the end tube on the surface of steel sheet the punch with nose radius of $2 \mathrm{~mm}$ was used, to flare the overhang specific distance (tube lip height) of the upper end of the deformed tube. The boss is formed at the portion length between the lower surface of the sheet and the upper surface of the die shown in figure. The new design of the punch is used to control the internal tube diameter and prevent the inward tube flow. Fig. 7 shows photograph of set-up of joining attachment on the universal testing machine. The experimental joining process was carried out at deformation speed is 5 $\mathrm{mm} / \mathrm{min}$. The accuracy of the load cell and displacement measurements of the testing machine was used are $\pm 0.5 \%$. and $0.0005 \mathrm{~mm}$ respectively. 


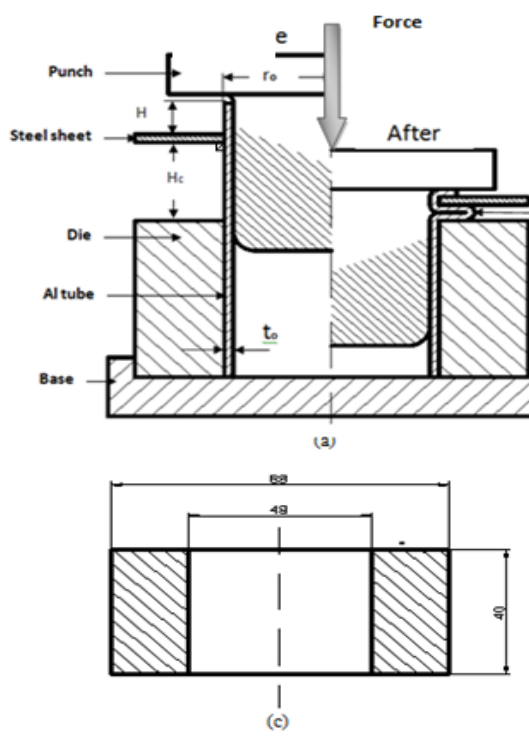

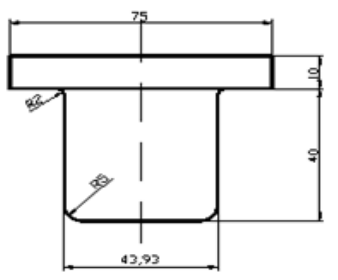

(b)

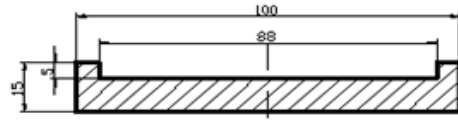

(d)
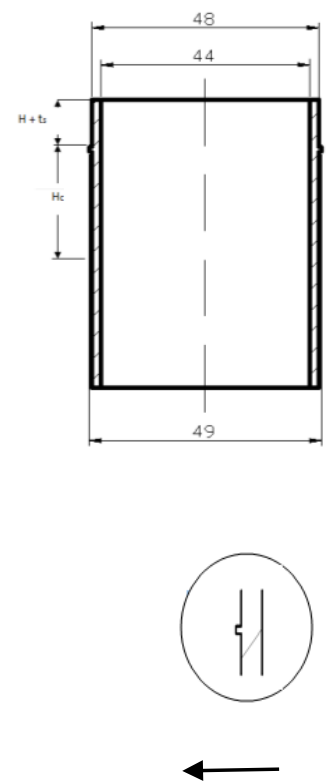

Fig. 6: Schematic of the Set-up and Set-

up part details
a) Set-up
b) Punch
c) Die
$\begin{array}{ll}\text { d) Base } & \text { e) Workpiece }\end{array}$

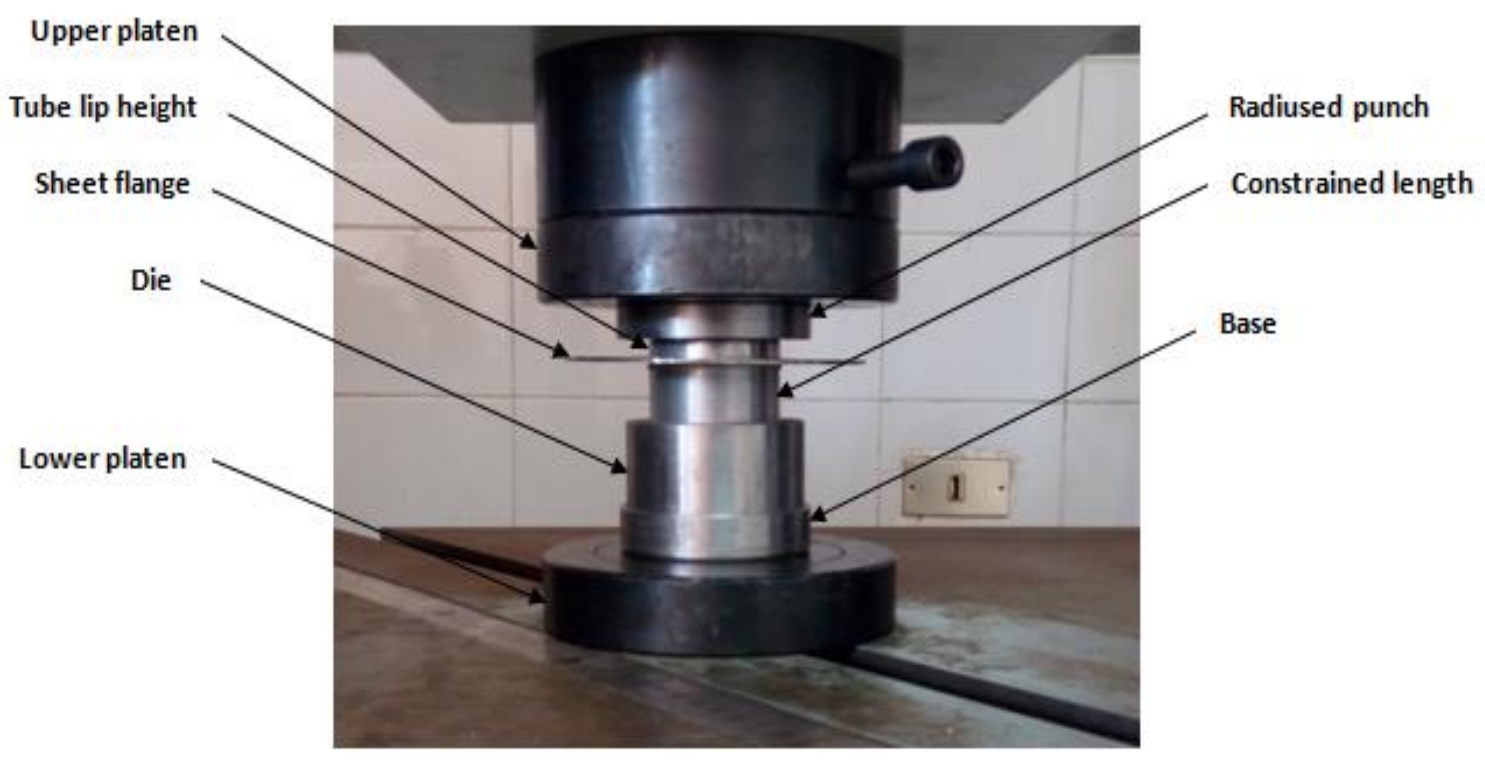

Fig. 7: Photograph of set-up joining attachment 


\section{EXPERIMENTAL RESULTS AND DISCUSSION}

\subsection{Experimental load displacement curve and material flow.}

Explanation of the stages in Fig. 8 is given as follows: Firstly, the punch inserted in the deformed tube, where the top of the tube lip height will contacted with the punch nose radius and hence moves along it. With the advancement of the punch, the tube lip height metal will move along the nose punch curve tail reaches the straight lower punch surface. Then the metal will forced to flow between the lower punch surface and the upper steel sheet surface. After that, the boss forming stage begins to form until the two folds begin close. Where, the joining required load will increase until the upper tube lip complete closing over the steel sheet. The configuration of the load/displacement curve changes due to reduce the deformation points at smaller constrained length. Decreasing the constrained length, the interference between the axial compression stage and the seaming stage during carrying out the process has occurred.

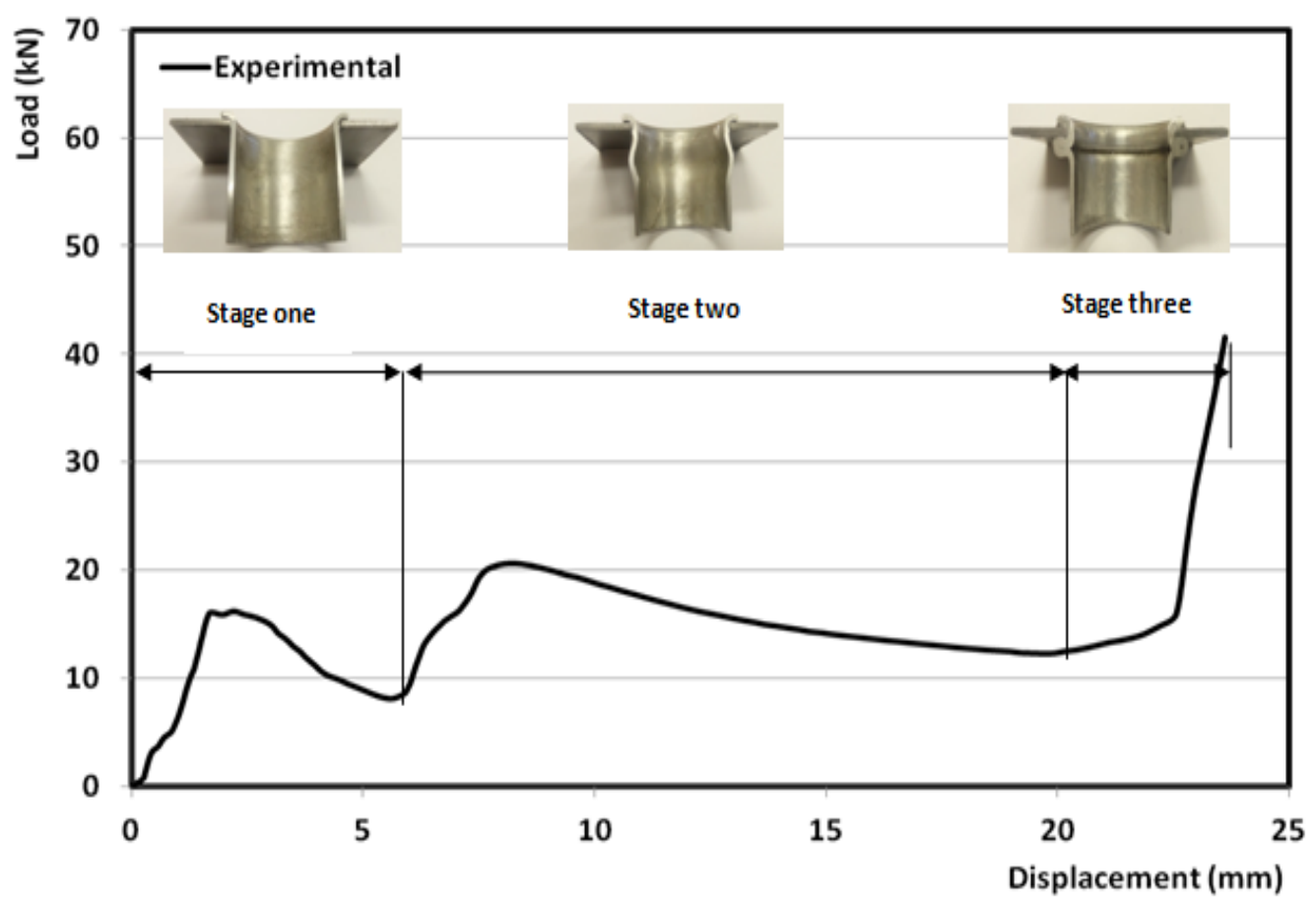

Fig. 8: A sample of the experimental stages of single pass plastic deformation joining process at Tube lip height $8 \mathrm{~mm}$, constrained length $20 \mathrm{~mm}$ and punch nose radius $2 \mathrm{~mm}$

Fig. 9 (a \& b) shows photos of sectioned joint part with and without new punch design. It is observed that, the diameter of the joint at lower boss part decrease due to the material flow inside and results in reduce diameter at this part.

Fig. 10 shows the experimental load/displacement curve of the joining process at different constrained length, different tube lip height and punch nose radius $2 \mathrm{~mm}$. It is noticed that, at large constrained length three different stages appears. On the other hand, with smaller constrained length the interference between second and third stages is observed followed by increasing the deformed required load. 


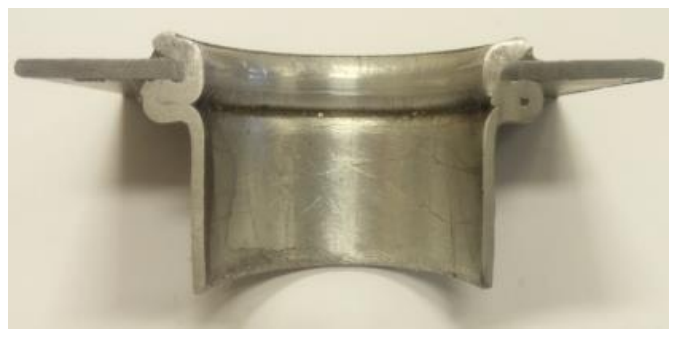

(a)

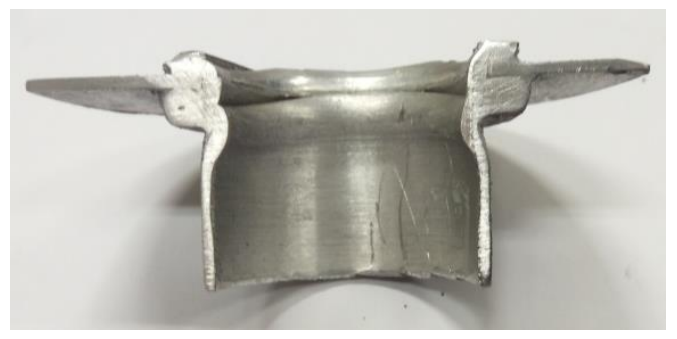

(b)

Fig. 9: Photo of joint part with and without new punch design.
(a) With new punch.
(b) Without new punch.

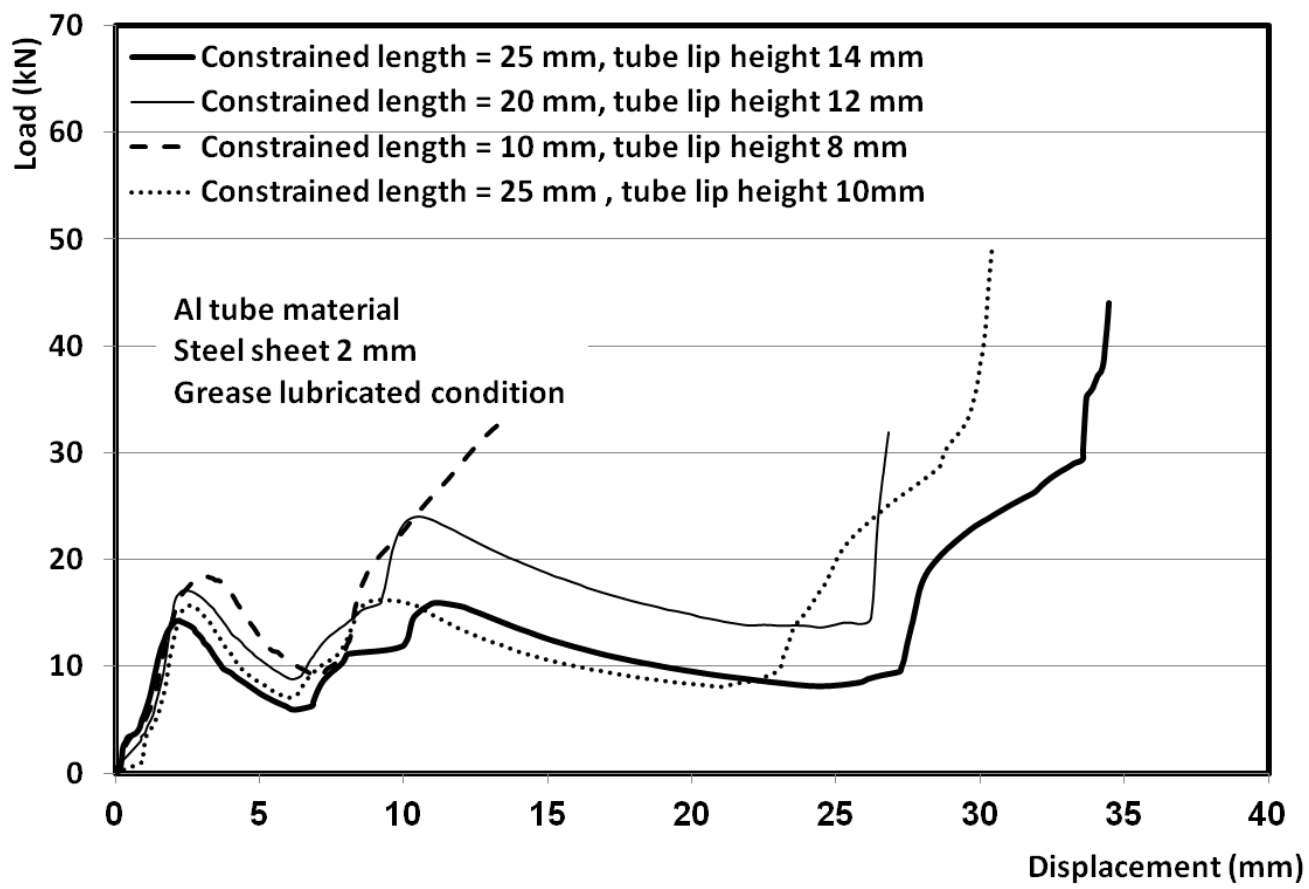

Fig.10: Experimental Load displacement curve of single pass plastic deformation joining process different tube lip height, different constrained tube length and punch nose radius $2 \mathrm{~mm}$

\subsection{Comparison between FE-Predicted and Experimental results}

Figure 11 shows the comparison between FE-predicted and experimental load displacement curve. It is observed that, in the first stage, the increasing rate of the load/displacement curve is similar to that of an external flare-bending. A maximum load of approximately $18 \mathrm{kN}$ in FE-predicted, while $17 \mathrm{kN}$ in experimental (referred to $\mathrm{A}$ and $\mathrm{B}$ ), respectively is obtained as the tube lip moves along the punch nosed due to the applied load. Hence, the tube lip starts curls in order to match the contour of the nose punch. Therefore, the load continuously decreases in this region to reach $9.5 \mathrm{kN}$ in FE-predicted and $7.5 \mathrm{kN}$ in experimental (referred to $\mathrm{C}$ and D), respectively. The second stage begins when the constrained length loaded axially due to the effect of axial compressive load without buckling, reaches maximum axial load approximately $20 \mathrm{kN}$ in FE- predicted while $17 \mathrm{kN}$ in experimental (referred to $\mathrm{E}$ and $\mathrm{F}$ ), respectively. As the punch moves 
down-ward, the load decreases to reach a minimum value of $13 \mathrm{kN}$ in FE-predicted and $9 \mathrm{KN}$ in experimental (refer to $\mathrm{K}$ and $\mathrm{L}$ ), respectively. Hence, the third stage (flarebend and boss forming closing) reaches to maximum load value of nearly $40 \mathrm{kN}$ in both FE predicted and experimental (refer to $\mathrm{G}$ and $\mathrm{H})$, respectively, and then suddenly increases at the end of stage. It is observed from the comparison that, good agreement between finite element and experimental results data is obtained. On the other hand, it is observed that, with increasing the tube lip height, the upper tube end will curl before the start of the touch with the steel sheet upper surface, with increasing the constrained length two folds that appears under the flange steel sheet. Fig. 12 shows the comparison between the experimental and FE-predicted results of the deformation stages. It is noticed that, identical shape in first, second and third deformation stages was obtained.

Figure 13 (a, b, c, d, e and f) shows the experimental and FE-predicted from the load/displacement curves of test cases with punch nose radius of $2 \mathrm{~mm}$. It is observed from these curves that, good agreement with the trend of all curves between the FEpredicted and experimental data are observed, where the difference between the data obtained at the peaks and valleys is ranging around $20 \%$.

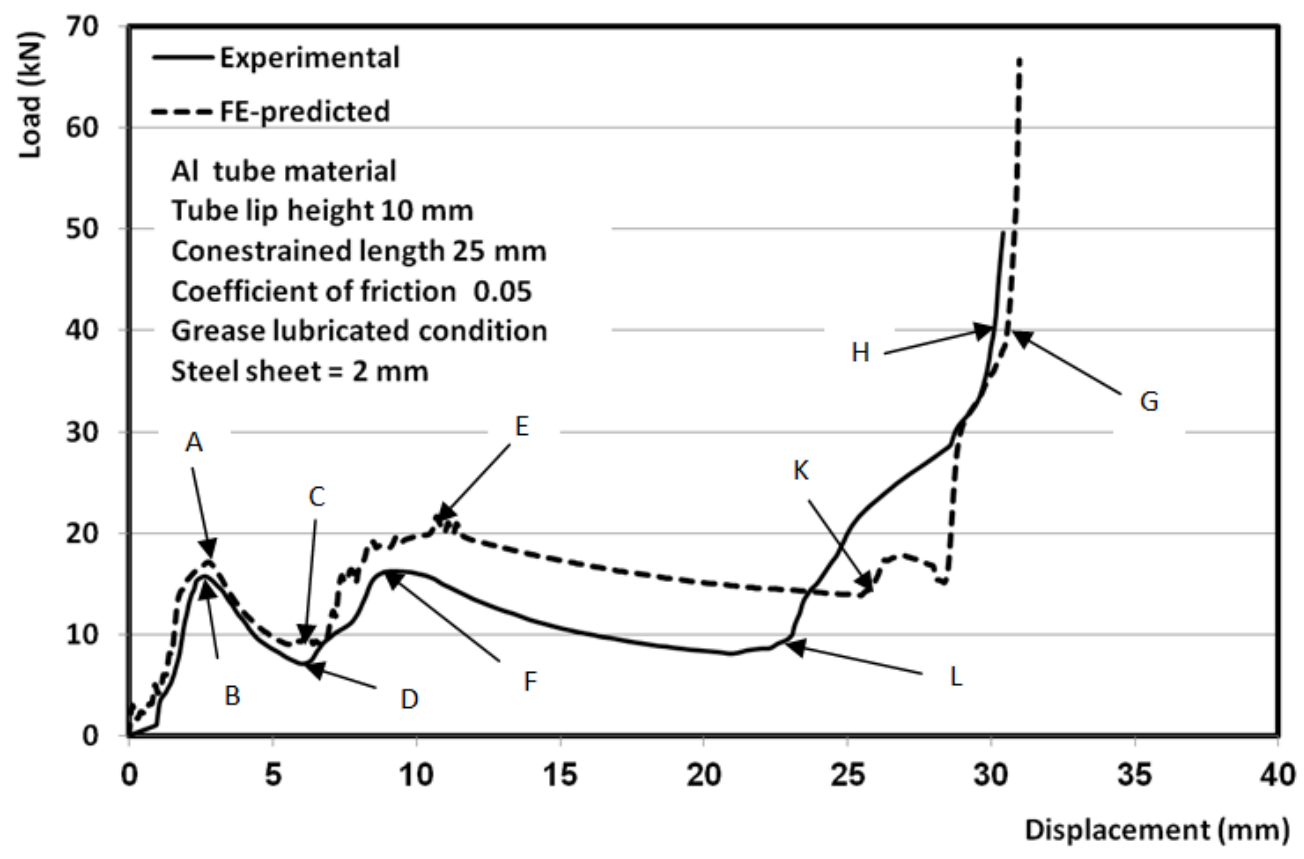

Fig.11: Experimental and FE predicted of the load/displacement curve, tube lip height $8 \mathrm{~mm}$, constrained length $25 \mathrm{~mm}$, punch nose radius $=2 \mathrm{~mm}$, coefficient of friction 0.05 and grease lubricated condition 
Vol. 40, No. 1. January 2021

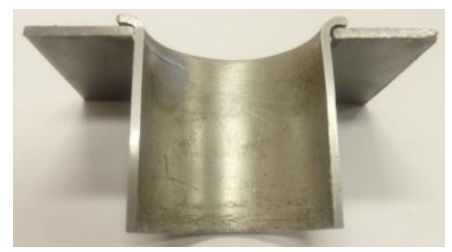

After stage one

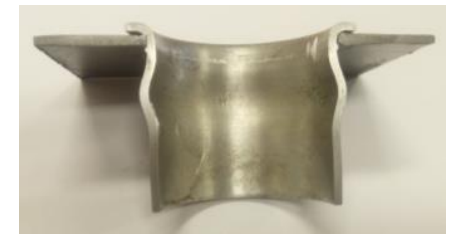

After stage two

(a)

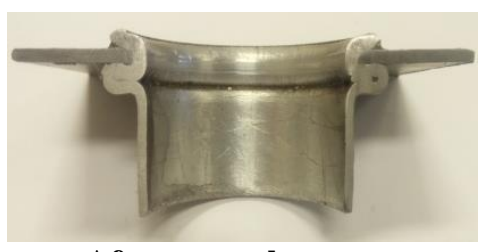

After stage three

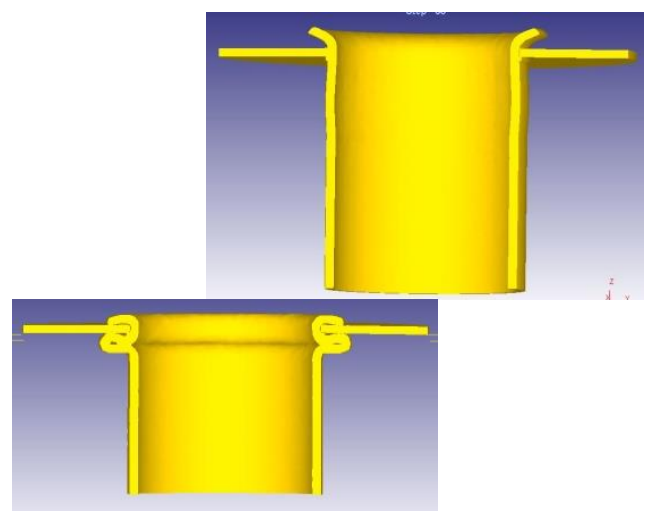

After stage one
After stage two

(b)

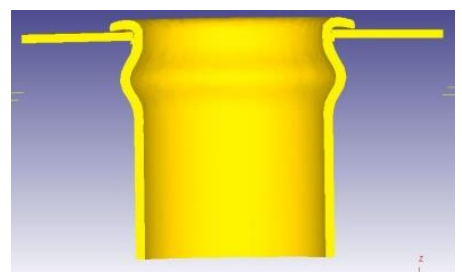

Fig.12: Photo of single pass plastic deformation of steel sheet to $\mathrm{Al}$ tube joining stages, tube lip height $=8 \mathrm{~mm}$, constrained length $=20 \mathrm{~mm}$ and punch nose radius $=2 \mathrm{~mm}$, a- Experimental, b- FE-simulation

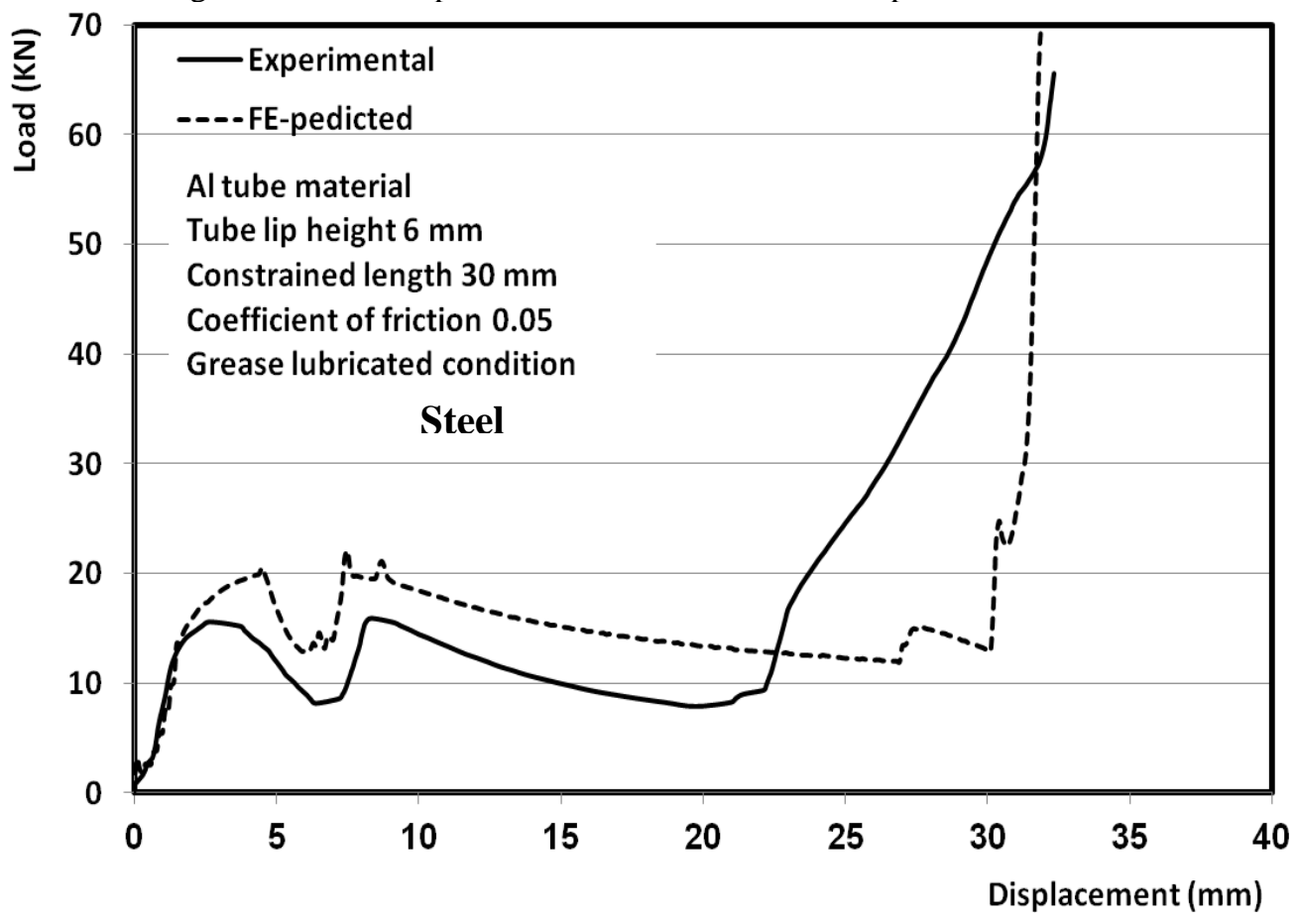

Tube lip height $\mathbf{6} \mathrm{mm}$ and constrained length $\mathbf{3 0} \mathrm{mm}$

(a) 
Vol. 40, No. 1. January 2021

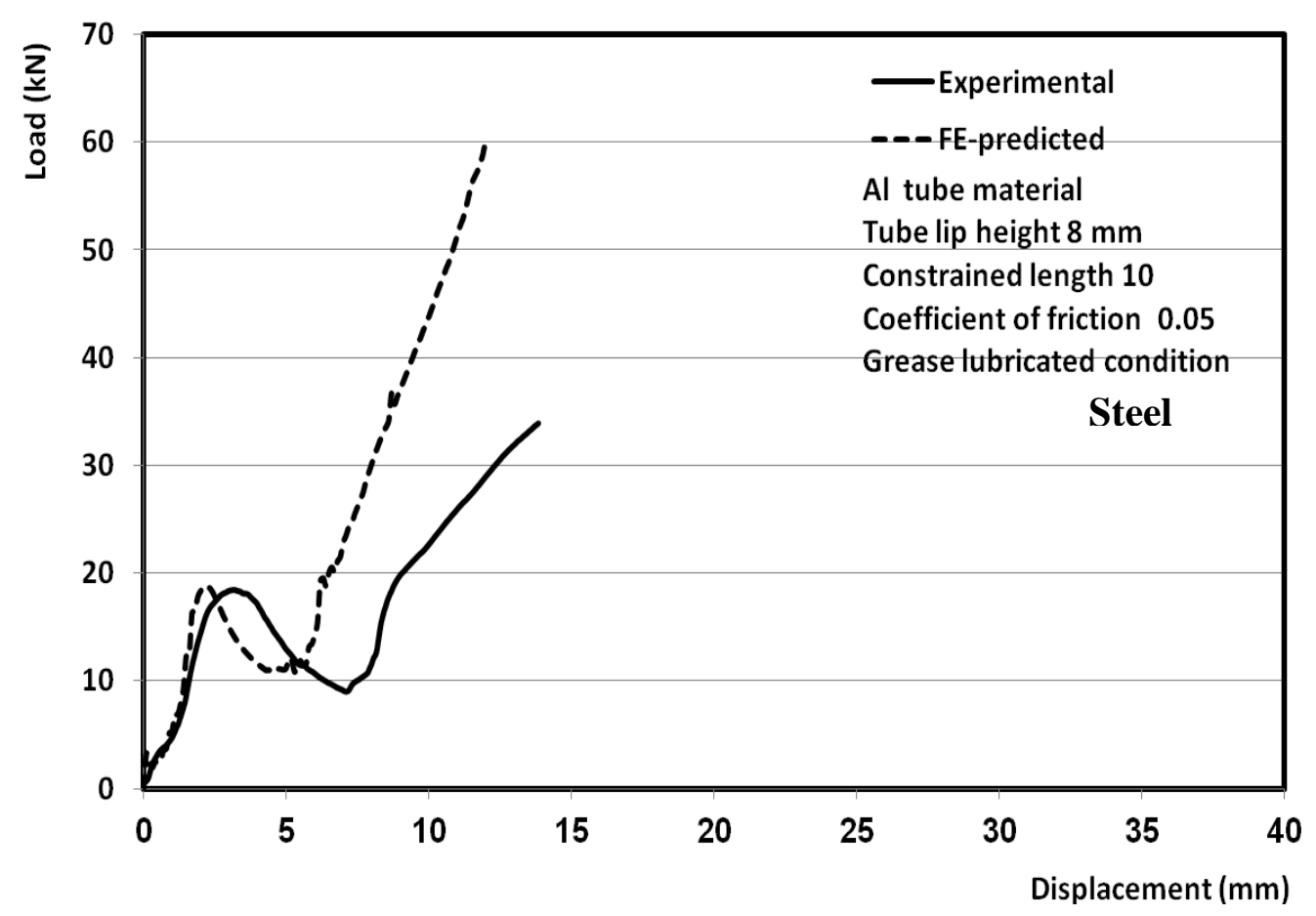

Tube lip height $\mathbf{8} \mathrm{mm}$ and constrained length $\mathbf{1 0} \mathrm{mm}$

(b)

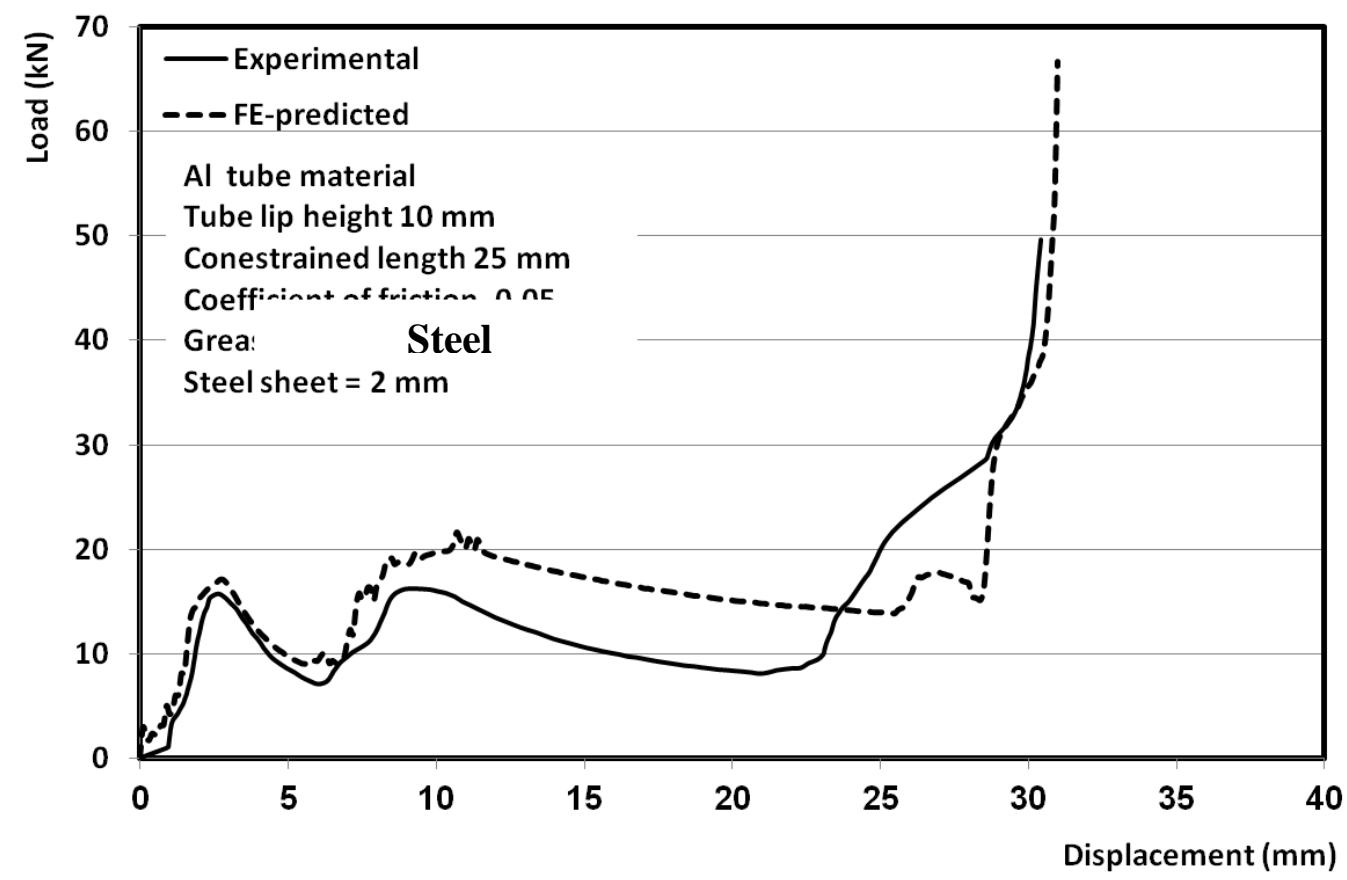

Tube lip height $10 \mathrm{~mm}$ and constrained length $\mathbf{2 5} \mathrm{mm}$

(c) 
Vol. 40, No. 1. January 2021

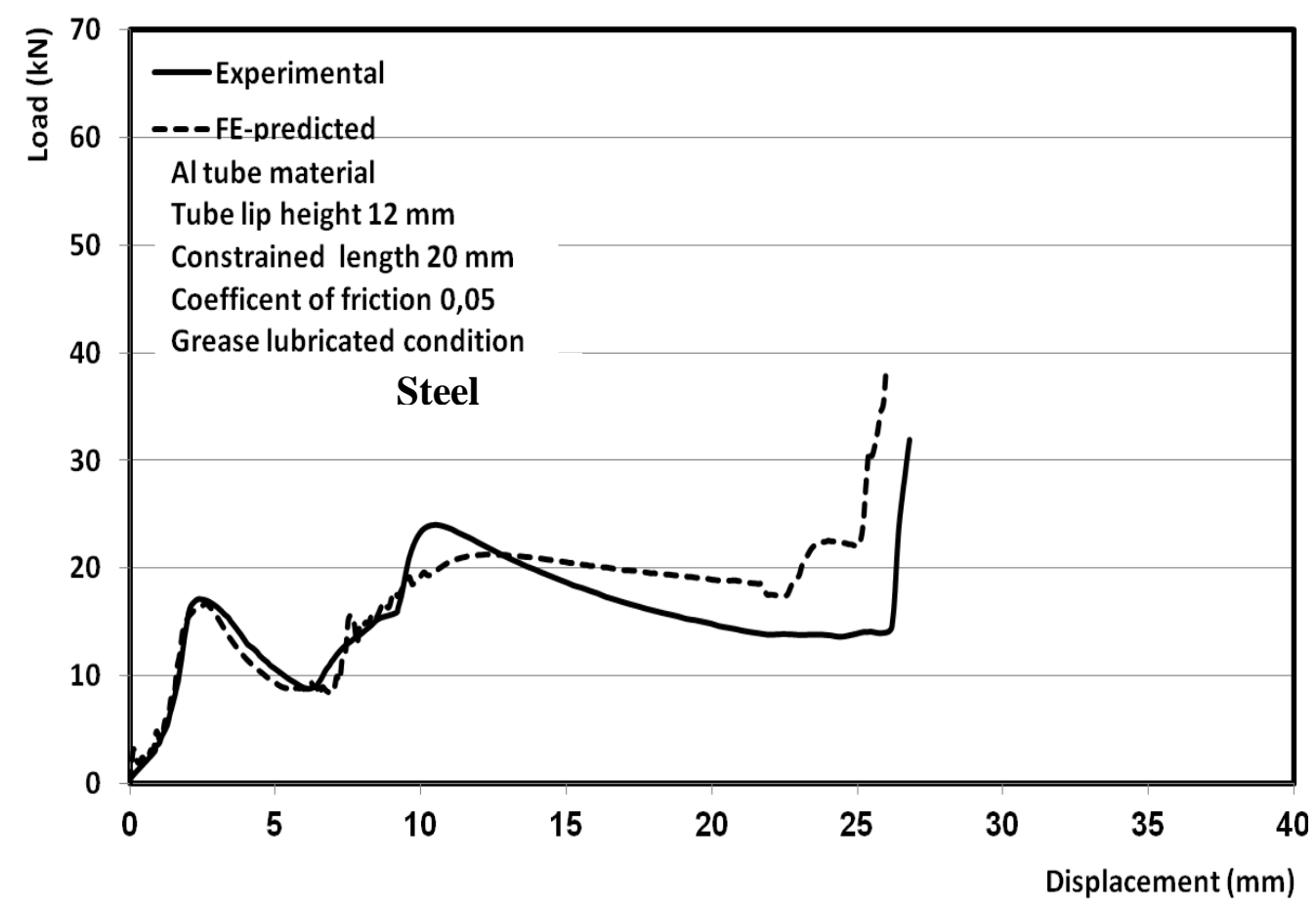

Tube lip height $\mathbf{1 2} \mathrm{mm}$ and constrained length $\mathbf{2 0} \mathrm{mm}$

(d)

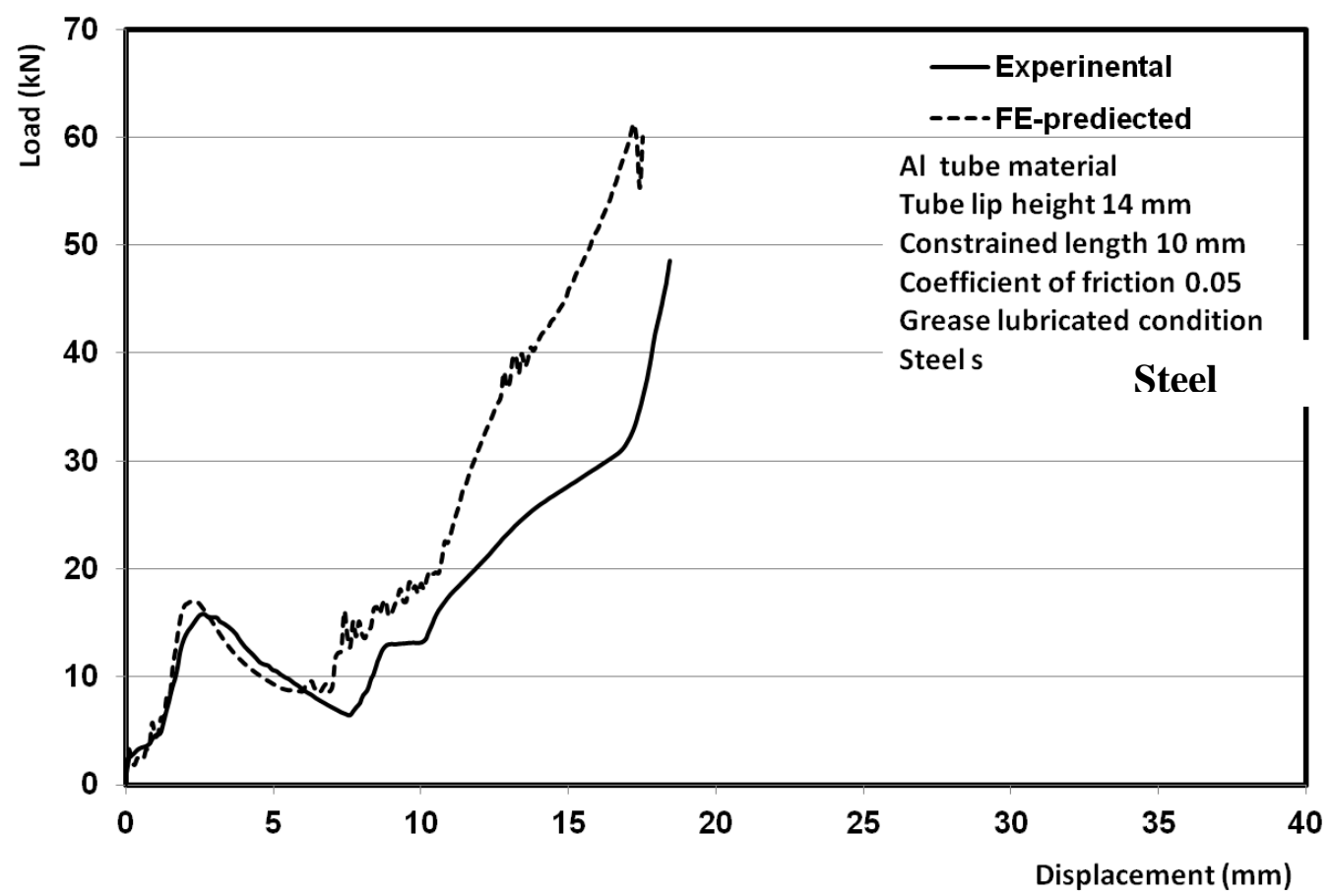

Tube lip height $\mathbf{1 4} \mathrm{mm}$ and constrained length $\mathbf{1 0} \mathrm{mm}$

(e) 
Vol. 40, No. 1. January 2021

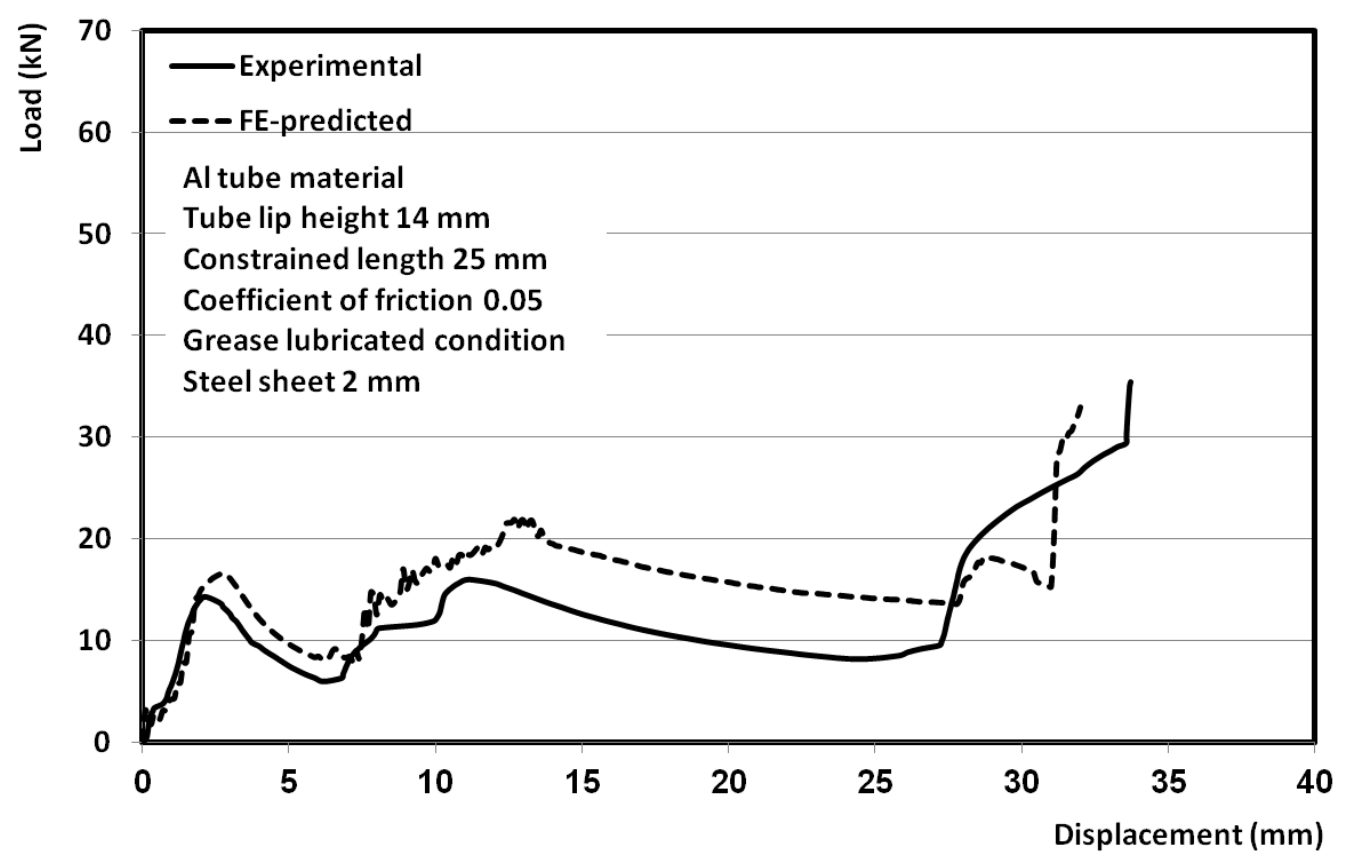

Tube lip height $14 \mathrm{~mm}$ and constrained length $25 \mathrm{~mm}$

(f)

Fig. 13: Comparison between FE and experimental load/displacement curves

\section{CONCLUSIONS}

This paper presents a single-pass plastic deformation joining process of $\mathrm{Al}$ tube to steel sheet. The following conclusions can be drawn:

1- The process has succeeded in producing a tube-sheet joint in one pass instead of two separate passes, saving both effort and money.

2- From the FE simulation, the tube passes through several stages, partial flare-bend of the upper tube lip, followed by the axial compression of the constrained tube wall and seaming of the tube bend on the sheet surface, then sealing the folds of the tube with each other. This was verified experimental.

3- The constrained length has great effect on the configuration of the load displacement curve. Decreasing the constrained length, the interference between the axial compression stage and the sealing stage during carrying out the process has occurred.

4- Good agreement between FE predicted and experimental results are obtained at earlier stages.

\section{Acknowledgement}

The experimental work described in this paper was performed at the Material Forming Lab, Faculty of Engineering, Minia University, Minia EGYPT. Thanks are due to Laboratory staff, for help my in conducting the experiments. 


\section{Vol. 40, No. 1. January 2021}

\section{REFERENCES}

[1] Alves L.M, Gameiro J., Silva C.M.A., Martins P.A.F., Sheet-bulk forming of tubes for joining applications, Journal of Materials Processing Technology 240, 154-161, 2017. https://www.sciencedirect.com/science/article/pi $\mathrm{i} / \mathrm{S} 0924013616303442$

[2] Alves L.M., Silva C.M.A., Martins P.A.F., Joining of tubes by internal mechanical locking, Journal of Materials Processing Technology, 242, 196-204. 2017.

https://www.sciencedirect.com/science/article/pi i/S0924013616304320

[3] Alves L M, J. D Eduard, Martins A.F. P., Joining sheet panels to thin-walled tubular profiles by tube end forming, Journal of Cleaner Production 19, 712-719, 2011.

https://www.sciencedirect.com/science/article/pi i/S0959652610004671

[4] Alves L. M., Afonso R.M., Silva C.M.A., Martins P.A.F., Boss forming of annular flanges in thin-walled tubes, Journal of Materials Processing Tech. 250, 182-189, 2017.

https://www.sciencedirect.com/science/article/pi i/S0924013617302832

[5] Alves L.M. , Nielsen C.V., Silva C.M.A., Martins P.A.F. Joining end-to-end tubing of dissimilar materials by forming, International Journal of Pressure Vessels and Piping 149, 24-32, 2017.

https://www.sciencedirect.com/science/article/pi $\mathrm{i} / \mathrm{S} 0308016116303970$

[6] Goncalves A. , Alves L.M., Martins P.A.F., Tube joining by asymmetric plastic instability, Journal of Materials Processing Technology 214, 132- 140, 2014 https://www.sciencedirect.com/science/article/pi i/S0924013613002495.
[7] Zhu S., Zhuang X., Zhu Y., Zhao Z., Thickening of cup sidewall through sheet-bulk forming with controllable deformation zone, Journal of Materials Processing Technology. 262, 597-604, 2018.

https://www.sciencedirect.com/science/article/pi i/S0924013618303327

[8] Alves L.M., Martins P.A.F., Single-stroke mechanical joining of sheet panels to tubular profiles, Journal of Manufacturing Processes 15, 151-157, 2013.

https://www.sciencedirect.com/science/article/pi i/S1526612512001028

[9] Zhang Q., Jin K., Mu D., Tube/tube joining technology by using rotary swaging forming method, Journal of Materials Processing Technology 214, 2085-2094, 2014.

https://www.sciencedirect.com/science/article/pi i/S0924013614000430

[10] Alves L.M., Afonso R.M., Silva C.M.A., Martins P.A.F., Joining tubes to sheets by boss forming and upsetting, Journal of Materials Processing Tech. 252, 773-781, 2018.

https://www.sciencedirect.com/science/article/pi i/S092401361730496X

[11] HaiYan Yu, JiaXu Li1, ZeZhen He, Formability assessment of plastic joining by compression instability for thin-walled tubes, The International Journal of Advanced Manufacturing Technology, 97, 3423-3430, 2018.

https://link.springer.com/article/10.1007/s00170 -018-2128-1

[12] Kitamura K, Hirota K., Ukai Y., Matsunaga K. \& Osakada K., Cold joining of rotor shaft with flange by using plastic deformation, CIRP Annals, Manufacturing Technology, 61, pp. 275-278, 2012.

https://www.sciencedirect.com/science/article/pi $\mathrm{i} / \mathrm{S} 0007850612001011$ 


\section{وصل انبوبة بلوح لمعادن غير متشابه فى مشوار واحد بعملية تثكيل لان مركبة}

تتطلب التطبيقات الصناعية الوصل بأستخدام التشكيل اللدن للمواد المتشابة والغير متشابه مثل خطوط نقل الموائع ، صناعة اجزاء الطائرات والسيارات. فى هذا البحث اقترح اسلوب جديد لوصل الاقراص المعدنية مع الانابيب للمعادن الغير متشابه فى مشوارواحد. ويتم الوصل بأحكام لوح المعدن بين الطية والثفة العلوية للانبوبة. تم فحص تأثير الطول المقيد وارتفاع الشفة

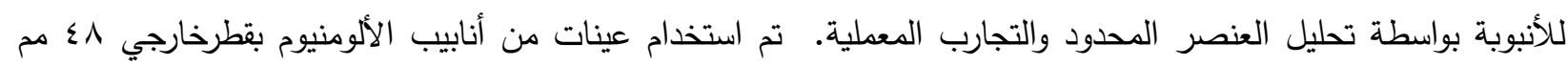

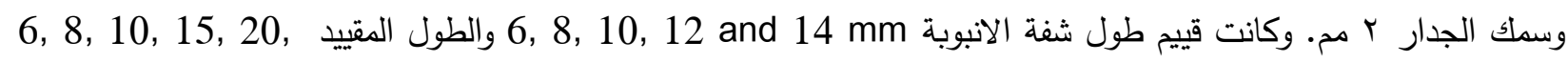
25, 30 and 35 mm لتشكيل جزء الطية. كما استخدم ضاغط بنصف قطر تقوس صغير لاحداث تثكيل انحناء حاد لثفة الانبوبة على سطح لوح المعدن وتجنب لف شفة الانبوبة. وتمر الانبوبة بعدة مراحل حتى يتم وصلها مع قرص المعدن : الانحناء الجزئى ، التشكل الجزئى للطية واخيرا مرحلة الاغلاق. تم اقتراح تصميم جديد للضاغط للتحكم في قطر الأنبوب الداخلي ومنع سريان معدن الانبوبة الى الداحل أثثاء عملية التشكيل لتحسين جودة الوصلة. وأظهرت المقارنة اتفاقاً جيداً بين تحليل العنصر المحدود والتجارب العملية فيما يختص بمراحل التشكيل واتجاة منحنيات الحمل / الإزاحة. 